\title{
El señor guardará tus salidas y entradas: lectura teológica del Salmo 121*
}

\author{
Mariana Zossi**
}

Recibido: 1 de mayo 2014 • Aprobado: 13 de julio 2014

\section{Resumen}

El Salmo 121 habla específicamente de un camino difícil, como de un peregrinaje. Se celebra al Señor como Aquel que es mi auxilio, el de los peregrinos en el viaje a casa o a la casa de Yahvé. El Señor no duerme, los protege, los guarda en la cuesta y vela por la vida de cada uno.

Asimismo, con la importancia del motivo del Éxodo en la teología de Israel, este salmo puede expresar el cuidado y la protección del Señor en el viaje por el desierto hacia Canaán, con lo cual los peregrinos al recitarlo se identificarían con sus antepasados en la marcha a la Tierra Prometida, el lugar de la morada del Señor.

Palabras clave: auxilio, Éxodo, salir, entrar, confianza, esperanza.

* Escrito resultado de investigación de la autora.

** Bachiller en Teología en Buenos Aires y licenciada en Ciencias Bíblicas y Arqueología en la Pontificia Universitas Antonianum en Jerusalén. Religiosa argentina de la Orden de Predicadores. En estos momentos es docente de Biblia de Antiguo Testamento y Nuevo Testamento del Seminario Mayor Arquidiocesano Nuestra Señora de la Merced y San José, de la Arquidiócesis de Tucumán, del Centro de Espiritualidad Santa María, Fundación Elmina Paz de Gallo, Universidad Católica de Santiago del Estero, Argentina. Es desde el 2009 guía en Peregrinaciones de Tierra Santa. Correo electrónico: mjzossi@gmail.com 


\title{
The Lord will watch over both your coming and going: Theological reading of Psalm 121
}

\begin{abstract}
Psalm 121 speaks specifically of a difficult journey, like that of a pilgrimage. The Lord is celebrated as my help, the pilgrims help on the journey home or to the house of Yahweh. The Lord does not sleep; He protects them, guards them on the uphill journey and watches over the life of each one.

Likewise, considering the importance of the Exodus theme in the theology of Israel, this Psalm could also express the care and protection of the Lord on the journey through the desert towards Canaan, so the pilgrims reciting it would identify themselves with their ancestors in the march towards the promised land, the site of the dwelling place of the Lord.
\end{abstract}

Keywords: Help, Exodus, exit, enter, confidence, hope.

\section{Le seigneur gardera tes entrées et sorties: Lecture théologique du Psaume 121}

\section{Résumé}

Psaume 121 parle spécifiquement d'un chemin difficile, comme un pèlerinage. Il célèbre le Seigneur comme Celui qui est mon aide, les pèlerins sur le voyage de retour ou de la maison de l'Éternel. Le Seigneur ne dors pas, protège, permet d'économiser sur les coûts et assure la vie de chacun.

En outre, l'importance de l'occasion de l'Exode dans la théologie d'Israël, ce psaume peut exprimer les soins et la protection du Seigneur dans la traversée du désert à Canaan, que les pèlerins de réciter identifier avec leurs ancêtres dans le mars vers la Terre promise, le lieu de résidence du Seigneur.

Mots-clés: Ajuda, Êxodo, sair, entrar, esperança, confiança. 
${ }^{1}$ Canción para las subidas.

Quiero alzar mis ojos a los montes, ¿de dónde vendrá mi auxilio?

${ }^{2} \mathrm{mi}$ auxilio del Señor, que hizo el cielo y la tierra.

${ }^{3}$ Que no permite resbalar a tu pie, que no duerme tu guardián.

${ }_{\text {i }}$ Mira, no dormirá, y no se adormentará el guardián de Israel!

${ }^{5}$ El Señor tu guardián, el Señor tu sombra, sobre tu mano derecha.

${ }^{6}$ Diariamente, el sol no te hará daño y la luna en la noche.

${ }^{7}$ El Señor te guardará de todo mal, (el Señor) guardará tu alma,

${ }^{8}$ el Señor guardará tu salir y tu entrar, desde ahora y por siempre.

\section{Introducción}

Los salmos son expresiones poéticas de una peculiar experiencia de fe. De manera apasionada, el salmista describe la cercanía y la lejanía de Dios, su acontecer en la historia, y cómo ésta repercute en la historia del hombre, a través de visiones, observaciones y actitudes que tejen su experiencia religiosa, y fluye en poema.

Cuando habla el salmista, lo hace desde su presente, caracterizado por una experiencia de desesperación o alegría, de humillación o renovación interior, de sumisión o libertad, y, a partir de esta realidad, evoca su plegaria con elementos teológicos, con el fin de fortalecer su fe en el poder salvífico de Dios.

Desde esta concepción, en los salmos no se desarrolla especulativamente un tratado de teología, sino que en estos la experiencia religiosa del poeta cataliza los grandes temas teológicos o paradigmáticos de la historia salvífica en el aquí y ahora, haciendo un uso libre de ellos para presentarlos como parte de su historia personal y la de su pueblo (Morla, 1994, p. 394).

Queremos exponer en este trabajo, los tres temas teológicos con los cuales el poeta del Salmo 121 quiere presentar el poder salvífico del Señor y su presencia constante en el caminar de su pueblo. Para poder desarrollar estos núcleos teológicos, vamos a trabajar sobre una estructura poética que presenta a los tres temas en un movimiento ascendente: desde la afirmación de fe en Yahvé "creador del cielo y de la tierra" (CEC, 198), el poeta reflexiona sobre la imagen del Señor como Guardián/Centinela de Israel que se manifiesta con gestos de cercanía y fidelidad hacia el hombre y su pueblo, para alcanzar, en un tercer momento, desde la certeza de la presencia del Señor en los caminos - (desiertos) de la vida de 
cada israelita, una bendición que se extiende no solo al 'ahora', sino también al 'siempre' ${ }^{1}$, y que se abre a un espacio de bendición sin límite en todas las salidas y entradas de la vida².

Solo a modo de referencia, ya que no es el lugar para un desarrollo más detallado, esta estructura poética nace principalmente de dos clases de análisis: uno sintáctico, propuesto por el prof. Niccacci en su "The Biblical Hebrew Verbal System in Poetry" (Niccacci, 2006) 3 , y la otra desde el estudio del Salmo 121 como con salmo mixto, pues es un salmo en el que se pueden reconocer varios estilos, que en su construcción común, tejen un movimiento característico ${ }^{4}$.

\section{Temas teológicos del Salmo 121}

\section{Yahvé creador del cielo y de la tierra}

La teología de la creación ocupa un lugar destacado en el salterio. En ocasiones, dice V. M. Asensio, “[...] todo se reduce a una ligera alusión; a veces nos

1 'Si 'para siempre' significaba 'de por vida' en el horizonte del autor y de algunas generaciones de orantes, un día 'para siempre' se prolongará más allá de la muerte, a otra vida duradera. No es deformación ni pérdida de sentido; es dar todo su sentido a las palabras”' (Schökel, 1989, p.7).

2 Los judíos piadosos suelen recitar el v. 8 de nuestro salmo al salir y entrar de sus casas, y besar con su mano la mezuzá, un pequeño cilindro de metal o de madera que se coloca a la derecha del poste de la puerta y que contiene un trozo de Deuteronomio 6, 4-9; 11,13-21, haciendo viva la memoria de la protección y cuidado constante de parte del Señor al peregrino fiel, y los Askenazíes lo rezan como "la oración del viajero". En cambio en la liturgia cristiana el Salmo 121 es proclamado en la oración de vísperas de los viernes de la segunda semana, en tercia los martes de la primera semana, en vísperas del oficio de los difuntos y en el ritual de la bendición de una nueva iglesia.

3 Al considerar las formas verbales del yigtol (tanto volitivas como indicativas) como pertenecientes al eje temporal del futuro, lo que posibilita una apertura del tiempo sin límite, como lo expresa el sintagma final del salmo. Así los movimientos temporales en la comunicación del poema, permiten percibir que una verdad del pasado, "que hizo el cielo y la tierra", puede ser vivida como una experiencia en el presente, "mi auxilio del Señor — el Señor tu guardián - el Señor tu sombra", abierta al futuro como esperanza, como una certeza en el deseo de bendición que vive el salmista en su inseguridad humana, expresada claramente en la inminencia de un viaje: "pasos en el camino" (v. 3), "partida y regreso" (v. 8), "viajar de día y de noche" (v. 5).

4 La súplica individual, presente en el v. 1, se abre a una atmósfera de confianza que se describe en los vv. 2-6 en una manera ascendente, espiritual y literariamente, sostenida por la imagen de la ascensión a Sión, propia de los salmos de subida, hasta alcanzar en los vv. 7-8, en una auténtica bendición, que se extiende en un acontecimiento espacio-temporal sin límites. 
encontramos con un amplio desarrollo temático. Pero el interés siempre se centra en el paradigma Dios para el hombre - el hombre para Dios" (Morla, 1994, p. 394).

El poeta, en el Salmo 121, tiene conciencia de que el poder creador del Señor actúa eficazmente en su acción salvífica y así lo expresa cuando el salmista, alzando su mirada hacia las montañas, se pregunta ¿de dónde me vendrá el auxilio?

Las montañas presentan dos categorías de comprensión, una positiva y otra negativa. Desde el punto de vista positivo ${ }^{5}$, significan protección (Gn 19,17; Dt 33,15), fuente de alegría y paz (Is 55,12; Ez 34,13-14), representan el lugar donde habita Yahvé, lugar del Templo y, por lo tanto espacio de llegada y renovación de la esperanza (Sal 87,1; 125,1-2; 133,3); en otros casos, la referencia a las montañas alude al poder de Dios de controlarlas y dominarlas ${ }^{6}$ (Dt 32,22; Is 41,15). En cambio, desde una comprensión negativa, a los montes se los interpreta como lugares de peligro y dificultades para los que están en camino y como santuario y morada de los falsos dioses ${ }^{7}$.

Hay buenas razones para leer el salmo, incluyendo tanto los aspectos positivos como los negativos. A medida que el peregrino mira las montañas, las ve como un lugar en el que deposita su miedo y esperanza. Contienen peligro y, sin embargo, la salvación. Eran la residencia de bandidos, animales salvajes y santuarios paganos, pero también la residencia del Templo y de Yahvé.

La pregunta retórica, ¿de dónde vendrá mi auxilio?, realizada frente a las montañas, con su potencial de peligro y al mismo tiempo de espera, plantea a los peregrinos el origen de la ayuda y auxilio. Sin importar si se considera la pregunta como una expresión indirecta, para ver de dónde vendrá el auxilio, se reconoce de una manera más clara la ambivalencia de la situación que vive el peregrino desde un sentimiento de miedo y a la vez de esperanza.

El término auxilio en muchos casos se refiere a la confianza en la intervención militar, que se concreta en la ayuda de Dios en la batalla (1 Cr 12,18; 2Cr 14,10; Is $63,5)^{8}$. En otras ocasiones se utiliza para expresar la asistencia personal de Yahvé

5 A. Ceresko ve en el salmo las raíces de la oración de un guerrero que conocía muy bien que la protección de Yahvé estaba estrechamente asociada con las colinas y los acantilados de la montaña. Las colinas son vistas como una fuente positiva de la fuerza protectora del Señor, fortaleciendo de esta manera una lectura positiva del salmo (1989, p. 508).

6 Dios es también Señor de las montañas (El-Shadday) (Leon-Dufour, 1996).

7 Según la terminología oriental el Hermón, Tabor y el Safón (monte sacro ugarítico) son los montes sacros idolátricos, residencias de las divinidades paganas.

8 A. Ceresko, refiriéndose a la historia temprana de Israel, comprende las montañas como el lugar propicio donde crecían las guerrillas, contra las cuales debían luchar la Confederación de 
a los más necesitados, enfermos o desesperados (Is 50,7.9); y es específicamente en el salterio donde se profundiza esta última comprensión, cuando el salmista reconoce la acción divina en los menos privilegiados (Sal 10,14; 72,12) y en su misma persona (Sal 28,7; 86,17).

En la primera parte del Salmo 121, la fe en la ayuda de Dios está motivada por esa potencia creadora, que recibe la impronta de la tradición cultural que comprende la creación y la salvación (bendición). Lo específico de la fe veterotestamentaria de la creación surge aquí de manera clara: todo nace de las manos de Dios; por lo tanto, en él reside la potencia para el auxilio y, aún en el presente, todo está en sus manos. En consecuencia, el salmista se siente creatura en esas mismas manos.

Para Israel, la creación no es un objeto, sino un acto divino ante el cual Dios siempre se mantiene distinto, permanece en él, lo mantiene en su ser y lo conserva en la existencia (Sal 104) (Kraus, 1985, p. 46).

Otra particularidad de esta fe en la creación se centra en que Dios crea por medio de la palabra (Sal 33, 6.9); la palabra no solo es la única continuidad entre Yahvé y el mundo, sino que a través de esta el hombre puede acceder al conocimiento de la creación. Es la misma Palabra de Yahvé la que creó el mundo y que da a conocer el mundo como creado. Por lo tanto, son el cielo y la tierra los que hablan del Creador: "[...] lo creado por Yahvé no es mudo, sino que dice algo que es escuchado hasta los confines de la tierra" (Kraus, 1985, p. 47). Las obras de la creación, sugeridas en el Salmo 121 en el merismo cielo y tierra, que expresa la totalidad de la creación ${ }^{9}$, narran la gloria de Dios (Sal 19,2), los cielos dan a conocer la justicia de Dios (Sal 145,10).

Tribus. Tomando 1 de Reyes $(20,23)$, recuerda cómo los sirvientes del rey de Siria culpaban de
su derrota a manos de Israel al que la batalla se había producido en la región montañosa donde
los israelitas se movían hábilmente. A partir de este concepto, y de la comparación del Salmo
121 con el Salmo 91, entiende toda la protección y cuidado por parte de Yahvé, mencionada
en el Salmo 121, como una oración de un guerrero que está por participar en una batalla. Esta
conclusión la reafirma con los comentarios de Simeón de Muis, quien declara "Este salmo es la
oración de un guerrero. Y por lo tanto creo que este salmo es de David o de algún otro poeta,
escrito mientras se realizaba una campaña". A su vez se apoya en las palabras de San Hilario
de Poitiers acerca del Salmo 121, versículo 5: "[él está] en tu mano derecha [...] mientras que
el poder de los demonios se oponen a nuestras luchas para debilitar y herir gravemente a las
mejores obras de nuestra fe, el cuidado vigilante de Dios está prometido, a tu derecha" (Ceresko,
1989, pp. 504-505).

9 P. Boccaccio afirma: “É noto che il complesso cielo e terra indica l'universo interno, per cui la lingua ebraica classica non ha termine peculiare"; (Boccaccio, 1952, p. 177). 
Este poder de autoexpresión de la revelación de Yahvé, que posee la creación, no lo tiene por sí misma, sino que lo recibe y no lo agota. Por el contrario, su testimonio introduce al misterio que solo se desentraña en la Palabra y en el nombre del Dios de Israel (Kraus, 1985, p. 48). Desde la fe en la creación, desde esta narración del cielo y tierra, nace el derecho y la fuerza para la intercesión (Weiser, 1984, p. 821).

El salmista, que habla en primera persona, se siente en peligro inminente de un viaje, expresado por medio del vistazo hacia los montes. En consecuencia, la imagen del AT del Pastor/Guardián que cuida a su pueblo, segundo punto de nuestra lectura teológica, se une a esta fe en la creación, ya que esta no radica en el hecho que la creación es un solo acto de Dios, sino en que hay un constancia en el gobierno divino sobre todo lo creado, siempre viviente y operante. La historia de la creación no está concluida, la actividad creadora de Dios se extiende al presente, y es fuente de fe para todo aquel que se encuentre en necesidad de cuidado.

Por lo tanto, la fe en el Creador no implica solamente aceptar una afirmación teórica sobre el origen del ser y la existencia, sino sobre todo que es adherirse con fe y esperanza a la persona de Yahvé. Cuando el Señor actúa contra los poderes que lo amenazan, Israel descubre su libertador en la creación. Esa imagen de Dios como creador se transforma así en una fuerza inmutable y firme ante las amenazas que lo asechan en el camino. Esta declaración constituye la base de las declaraciones de la confianza en el resto del salmo.

Cuando Dios vendrá a juzgar, dice el Midrash Tehillin, los hijos de Israel verán hacia los montes, es decir hacia los padres y maestros, para tomar de ellos su defensa; pero ninguno de ellos podrá salvarlos, porque solamente del Padre, que está en los cielos, viene la salvación ${ }^{10}$.

\section{Yahvé es el Guardián de Israel}

Como habíamos afirmado en el punto anterior, la creación no es un solo acto de Yahvé, sino una constante tutela por su parte en la historia de su pueblo.

10 "Cosa significa ai monti? Nel giorno nel quale il Santo, benedetto egli sia, verrà in giudizio e i Figli d'Israele guarderanno ai Padri affinché parlino in loro difesa, non ci sarà padre che possa liberare suo figlio, né uomo che possa liberare suo fratello. In quella tribolazione, nel giorno del giudizio, in quell'ora alzeranno gli occhi al loro Padre che è nei cieli e diranno: Perché tu sei nostro Padre, poiché Abramo non sa chi siamo e Israele non ci riconosce (Is 63,16)" (Lenzi, 2000, p. 79). A. Mello, comentando el Salmo 121, recupera también la interpretación rabínica diciendo: "Così dice il Santo - sia benedetto - ai figli di Israele: Ormai dovreste sapere chi è in grado di aiutavi: 'chi fa il cielo e la terra' (MT 505)" (Mello, 2008, p. 532). 
Israel siente que va haciéndose frente a ese acontecer del Señor en su vida; está pendiente de su intervención y actuación, que crea y hace posibles nuevos pasos y posibilidades. Por lo tanto, el tema de la creación para Israel está vinculado estrechamente con el de la historia de la salvación. Esta relación se expresa en la confesión de fe: "[...] mi auxilio [viene] de Yahvé, que hizo el cielo y la tierra".

A partir de este actuar salvífico de Dios en la historia de su pueblo, los israelitas experimentan protección, cuidado y sostén de la vida, y, en esas acciones, Yahvé se revela como el Señor y Rey de Israel. Afirma H. J. Kraus: “[t]oda la capacidad creadora de este Dios está volcada sobre su pueblo [...] es el mismo Dios el que libera a Israel y el creador de cielo y tierra" (Kraus, 1985, p. 85).

Al comienzo del v. 3 se habla, de una manera genérica, del cuidado, principalmente en referencia al caminar; pero, a medida que el poeta avanza en su descripción de la acción salvífica divina, el verbo cuidar comienza a esclarecerse y encuentra un eco en la historia del pueblo. La referencia a la tradición de la historia de su propio pueblo le sirve para demostrar que Dios continúa obrando en ella. Este, que "cuida y que no permite que tu pie resbale", es el Guardián de Israel, una fórmula muy cercana a la de Pastor de Israel del Salmo 80.

Aunque la imagen del pastor es muy frecuente en la Biblia, el título de pastor de Israel es único (cf. Gn 49, 24). El pastor, para la concepción religiosa israelita, no es simplemente el que conoce los caminos y sabe orientar hacia pastos verdes o conducir por caminos sin peligros (cf. Sal 23,1-3). Es, sin duda, un compañero de camino para aquellos con los que marcha, con quienes comparte las horas, los propios riesgos, la sed y el hambre: el sol los golpea igualmente a él y a su rebaño. Sin embargo, solo Él sabe brindar seguridad y certeza (Sal 23, 4). Dice G. Ravasi, "[...] la metáfora es transparente: solo el Señor es Pastor, a pleno título, como gustaban de repetir los profetas (Os 4,16; Jr 23,3; Is 40,11; 49,9)” (2002, p. 108).

El apelativo de pastor de Israel no es solo una expresión de la cultura del oriente medio, cuya población tiene características nómadas, sino que, sobre todo, es una referencia a la teología del Éxodo, a la peregrinación en el desierto y a la guía divina en medio del camino.

En medio de todas las vicisitudes que vive el pueblo en su camino por el desierto durante el Éxodo, el Señor se presenta como aquél que guía y protege a su pueblo y lo conduce hasta la "santa morada" (Ex 15, 13.17; 19, 4) (Magnate, 1991, p. 56).

La imagen del pastor se une a la del centinela en su vigilia nocturna: " $[\ldots]$ no duerme y no se adormece el guardián de Israel". La referencia es evidente, los centinelas, durante el día, guiaban al rebaño y, durante la noche, lo cuidaban de las aves rapaces o de los ladrones que atacaban sin piedad. 
El Señor no duerme ${ }^{11}$, vela constantemente por todos los miembros de su pueblo y no cesa ni un solo instante en su acción salvífica. Lo acompaña como un guardián, que sigue sus pasos con una despierta atención.

El centinela ejerce su función por la noche; es por eso que la descripción insistente del velar: el uso en tres ocasiones de los verbos dormir y adormecerse hace eco con las seis veces en que es usado el verbo cuidar o guardar, para describir la acción protectora del Señor. En este juego de palabras se vislumbra la presencia del Señor como la de un Dios vivo y vigilante. Esta imagen contrasta con la de los dioses que en cada cambio de estación caen en un profundo sueño. Estas divinidades eran "presas del dualismo vida-muerte, Baal vive y Baal muere. La divinidad es un poder que muere y vuelve a resucitar. Toda la vida participa del ritmo determinado por las estaciones del año" (Kraus, 1985, p. 220).

Yahvé no es como Baal, que permanece dormido ante la insistente oración de sus sacerdotes en el primer libro de Reyes $(18,27)$. El Señor no conoce el reposo en su acción de protección y defensa de sus fieles, no está sometido al sueño de la muerte, a diferencia de lo que ocurre en los pueblos vecinos y con sus dioses.

La noche se presenta segura en el salmo. En la noche la conciencia se retira de su función de vigilancia, se tiene necesidad de otro que vigile y vele, que tome el puesto de centinela y permita a la persona abandonarse a la "seguridad de la noche". Este eufemismo ${ }^{12}$ de la noche en el Salmo 121 se presenta poéticamente a través de las cuatro expresiones negativas de los vv. 3-4, por medio de una lítote $^{13}$. Mediante esta la noche, pudiendo ser concebida como oscura o luminosa, deja de lado la polaridad negativa del propio campo perceptivo y permanece luminosa para el caminante.

11 L. Jacquet presenta la exhortación parenética de San Agustín, con la cual recuerda la cercanía divina a los hombres que son asaltados por las tentaciones: "Dios nunca duerme: si quieres tener un guardián que no duerme, elige a Dios como guardián [...] Pero si nuestra fe duerme, Cristo duerme en ella; en quien la fe no duerme, Cristo vela" (P.L. 37, 1609,1611). Junto a las palabras de Agustín, el autor cita en las antípodas de la fe bíblica a un escritor francés, A. de Musset: “Dieu dort, et le monde est son rêve. Dieu dort, et [...] toutes les créations successives ou simultanées qui amusent son sommeil ne sont que des apparences [...] Quand Dieu s'éveillera, Il sera seul dans sa toute-puissante Unité. Les apparences tomberont dans leur néant primitif ; les simulacres des créations et des êtres [...] s'évanouiront a jamais. Dieu finira de 'rêver'" (Jacquet, 1975, p. 421).

12 El eufemismo se funda sobre la polivalencia del símbolo y es expresión de aquella polarización presente en toda percepción simbólica.

13 Expresión negativa de contenido positivo. 
Dios ha hecho una promesa de protección y seguridad a su pueblo, que se extiende por todo el pueblo (Sal 21,8 ; 30, 7; 62, 3-7; 81, 12-17; 125, 1-2). Adicionalmente es también el guardián, en una clara referencia a una relación personal, en la que Dios se preocupa amorosamente de cada uno, de cada una de sus ovejas en sus necesidades, dolores y enfermedades (cf. Ez 34,2-5; Zac 11, 16-17).

El Creador del universo, el Guardián de Israel atiende a una persona en particular ${ }^{14}$ que se siente amenazada desde el exterior, quién, a la vez, toma de la historia de su pueblo la fe en Dios, y participa en Él, que en esa historia está presente. Esta súplica personal se abre luego a una acción colectiva. Hay una conexión profunda entre el tú y la comunidad; en el mismo momento el Señor presta cuidado a un tú personal y al pueblo en su totalidad.

\section{Yahvé, Guardián de cada ser humano, en los caminos-viajes de la vida, llenos de dificultades y amenazas. Teología del Éxodo}

La presencia de Yahvé junto al camino de los peregrinos es invisible y, sin embargo, real y segura, a través de la protección de su brazo derecho (Dt 33,27); esta asistencia es una especie de extensión de la promesa anterior hecha a Abraham: "Yo estoy contigo; te guardaré por donde vayas" (Gn 28,15).

Algunos estudiosos ${ }^{15}$ comparan el viaje del pueblo de Israel desde Egipto a Canaán, el Éxodo, con las peregrinaciones a un santuario local o a Jerusalén, a través de una acumulación de imágenes y símbolos. De hecho, el término guardián, que guarda, utilizado seis veces en el Salmo 21, aparece en el relato del viaje del Éxodo de Josué:

Porque Yahvé nuestro Dios es el que nos hizo subir, a nosotros y a nuestros padres, de la tierra de Egipto, de la casa de servidumbre, y el que delante de nuestros ojos obró tan grandes señales y nos guardó por todo el camino que recorrimos y en todos los pueblos por los que pasamos. (Jos 24,17)

14 Diez veces resuena en el salmo el sufijo de la segunda persona del singular.

15 Cf. Ceresko (1989, pp. 507-508), G. Ravasi (2002, pp. 529-531), E. Haglund (1984, pp. 7-8; 102-103); T. Maertens afirma: “Le pèlerinage á Jérusalem prend donc l'allure d'un renouvellement de l'expérience du désert, il devient un petit 'Exode', conduit par le gardien divin, le même qui garde d'ailleurs Jérusalem" (Maertens, 1954, p. 54). 
Los peregrinos, al recitar este cántico en su camino hacia Jerusalén, a la 'casa' del Señor, no les era difícil imaginarse a sí mismos reviviendo la experiencia del Éxodo de sus padres, que también viajaron a la casa de Yahvé, a la tierra prometida (Ceresko, 1989, p. 507). Desde esta línea de reflexión, las montañas son figura de la montaña de Yahvé, el Horeb ${ }^{16}$, y las dos expresiones mi auxilio, con las cuales el Señor se revela como el libertador y salvador del pueblo, nos hacen memoria del rescate de Yahvé a Israel de la esclavitud de Egipto. Este rescate se profundiza con las afirmaciones de protección presentes en los vv. 3-6 que se conectan fácilmente con las condiciones vividas por el pueblo en su camino por el desierto; el Señor no permite que resbale tu pie (v. 3); no duerme, vigila el campamento (vv. $3 \mathrm{~b}-4)$; es refugio, sombra, ante los peligros del sol y de la luna en el desierto (vv. 5-6). En los vv. 7-8, Yahvé se manifiesta como aquel que va adelante del pueblo, que lo cuida de todo mal, y lo hace entrar en la tierra prometida.

Las expresiones polares, que se leen en los vv. 6-8, amplían esta lectura de peregrinación como símbolo del éxodo hacia una metáfora de toda la vida, todas

16 En la comparación entre el Horeb/Sinaí y las montañas hacia las cuales levanta los ojos y camina el peregrino, Sión, el prof. J. D. Levenson hace una contribución muy interesante, desde un enfoque centrado en el mensaje de la tradición judía. En concreto, sigue las tradiciones asociadas con las dos grandes montañas de la historia judía, Sinaí y Sión, y los pactos que las acompañan: la alianza mosaica y el pacto davídico. Levenson afirma que el Sinaí establece el escenario ideal para que Israel se reconozca a sí mismo, su relación con Yahvé, su relación con los extranjeros, y su relación con los otros dioses. En suma, el Sinaí ha de entenderse como la montaña de la identificación y definición. Pero en el desarrollo de la teología judía, nos encontramos con que las tradiciones que rodean el monte Sión lentamente van opacando el monte Sinaí. A esta transición, Levenson no la considera como una sustitución, sino como una continuación, en la que "Sinai was the mountain of Israel's infancy" (2009, p. 89) y Sión se convierte en el símbolo de la madurez de Israel como una nación. Según el autor, una de las distinciones entre Sión/el Templo con el Sinaí, está en una concepción cósmica, Sión es el punto de contacto de lo divino y de la humanidad. En esencia, "Jerusalem is simply the earthly manifestation of the heavenly Temple" (2009, p. 140), que se conecta con la creación y la perfección en su forma actual, sin tiempo y en el centro del mundo, como un lugar de importancia divina. Por último, en el tercer capítulo, Levenson describe la relación entre el Sinaí y Sión como una sucesión compleja. Argumenta que esta sucesión no es de orden cronológico (como si Sión sustituyese al Sinaí en importancia) ni geográfico (el norte se afianzó en el Sinaí, mientras que el sur en Sión); afirma que los fundamentos teológicos de estas dos tradiciones son complementarios, ya que cada uno enfatiza un aspecto diferente de la relación de Israel con Yahvé: Sión "inherited the legacy of Sinai" (2009, p. 206) y en muchos aspectos, continúa "the Sinaitic experience on a new mountain" (2009, p. 206). El Sinaí establece el pueblo de Dios y su relación con Dios, mientras que Sión sirve como punto de contacto entre el microcosmos humano y divino. Una relación entre las dos montañas percibida de esta manera, coloca a Israel en movimiento, en camino, hacia las promesas que se cumplirán en Sión, lugar de una nueva presencia, pero de una voz antigua, la del Sinaí: "the presence is the presence of Zion, but the voice is the voice of Sinai"; (Levenson, 1985, p.188). 
las salidas y entradas serán liberadas de todos los males y esto desde ahora y para siempre. El Señor está, vigila y guarda toda la vida del hombre, ante lo cual, cada uno puede fiar su vida en esa protección.

El Salmo 121 canta la experiencia del éxodo como un nuevo hecho que se abre a una bendición sin límite de espacio y de tiempo.

\section{La teología del éxodo como paradigma del Salmo 121}

L. A. Schökel habla que los patrones o esquemas en los textos bíblicos son muy conocidos, en los cuales se pueden identificar la tradición viva y están a disposición por el hecho de ser repetidos en diferentes contextos. Estos sirven para unificar los materiales y temas presentes en otros textos; esto se puede hacer para el caso del poema, estilizando el material recibido de la tradición. En su Manual de poética hebrea, propone dos sistemas que utiliza el escritor bíblico, por un lado, los esquemas propios de los géneros literarios, y por otro, los patrones tomados de las tradiciones históricas o de las instituciones sociales.

Dentro de estos últimos L. A. Schökel desarrolla el patrón del Éxodo, articulado básicamente en "salida de Egipto- camino por el desierto - entrada a la tierra prometida" (1980).

El Éxodo funciona como una estructura simbólica de un hecho nuevo, porque su realización histórica-corpórea fue vivida y leída como una acción trascendente. A partir de allí, los Israelitas comprendieron y asimilaron ese sentido trascendente, tomándolo como una expresión simbólica para construir y elaborar experiencias nuevas y semejantes, no solamente de situaciones históricas, sino también de "salidas" de enfermedades graves y de "entradas" al Templo para dar gracias (Schökel, 1980, p.12). Israel rehace las etapas de su historia, vuelve hacia atrás, "con un movimento diacrónico inverso" (Magnate, 1991, p. 21), para después volver al presente y desde allí abrirse al futuro.

La función que tiene el evento del Éxodo como patrón o arquetipo de otros textos, L. A. Schökel la llama generativa, ya que se convierte en fuerza y matriz para moldear otros hechos y momentos de la vida del pueblo, como si todo el conjunto literario del Éxodo se transformara en un paradigma teológico de una verdadera soteriología bíblica ${ }^{17}$.

17 M. Navarro Puerto habla del paradigma antropológico del Éxodo: “El Éxodo es un relato que narra un nacimiento, dato típicamente humano. Y lo narra en un paradigma que reproduce el esquema básico de la biografía humana: salir-atravesar-entrar. El ser humano va 
Este patrón se desarrolla en una estructura temporal de tres partes, aunque en muchos casos se presenta en una acción instantánea dentro de un esquema binario: salir-entrar. Dice L. A. Schökel que:

Los Israelitas salen para entrar, que no les basta salir por salir. Salir a un espacio abierto como el desierto, para vagar sin meta, no es la liberación que cuenta y canta el éxodo, y que se celebra en la liturgia. Vagar sin meta es una maldición, y es instructivo notar que el mismo verbo designa el vagar y el perderse o perecer. (Schökel, 1980, p. 60)

El sentido último del salir para entrar es alcanzar una bendición (cf. Gn 12, 1-3).

El esquema bíblico fundamental es salir-entrar, de modo que cada pieza se ha de comprometer en función de la estructura: el entrar como remate del salir, el salir como tensión hacia el entrar. Siempre se sale de un lugar, y el autor lo expresa así: el salir con una A y el lugar de salida con una $x$; el verbo llegar con una B y el lugar de arribo con una $z$; el tiempo intermedio con la C. Por lo tanto, el esquema podría verbalizarse de la siguiente manera: $\mathrm{A} x-\mathrm{C} y-\mathrm{B} z^{18}$.

El evento del éxodo nos proporciona un repertorio de símbolos, que en su carácter expansivo y polivalente, generan imágenes que fecundan el sentido y la forma como se debe comprender del texto. Entre algunos, nos parece ineludible presentar algunos elementos del paradigma del éxodo:

- Cuando el sujeto del acontecimiento es Dios, entra en primer plano el sentido teológico del hecho; la liberación es una salvación. La persona o el pueblo pasan de ser protagonistas a receptores de una acción divina. Este sentido teológico, se instala en un plano más profundo y no anula la realidad fenoménica de la salida.

haciendo su vida según este sencillo esquema espacial, simbólico, que se repite continuamente y que, a menudo, se invierte (entrar-pasar a través de-salir). Al nacer, el ser humano sale del vientre de su madre, atraviesa la vida y entra en la muerte. O, a la inversa: entra en la vida (nace), la atraviesa (vive) y sale (muere). El grupo de hebreos que había en Egipto, según el Éxodo, nace como pueblo en el paso del Mar. Para contarlo utiliza un paradigma simbólico antropológico: sale de Egipto, atraviesa el Mar y entra en el desierto. Pero si tomamos el relato en toda su extensión, el libro entero nos cuenta que el pueblo sale de Egipto (paso del Mar), atraviesa el desierto y se prepara para entrar en la Tierra Prometida" (Navarro, 1996, p. 23).

18 "Yo os saqué (A) de Egipto (x), os conduje (C) por el desierto (y) cuarenta años, para que conquistárais (B) el país amorreo (z) Am 2, 10" (Schökel, 1980, p. 16). 
- El lugar de la partida es Egipto, que es figura de esclavitud, de una situación negativa para el pueblo y para cada israelita en particular.

- Muchas veces, las acciones divinas se expresan con complementos circunstanciales, e indican el despliegue de poder liberador del Señor.

- Los verbos fundamentales son salir-entrar. Pero podemos encontrar otros que entran en la misma comprensión de sentido: aquí el verbo hacer subir, dentro del patrón del éxodo, es clave.

- Las preposiciones utilizadas marcan el movimiento de un desde a un hacia.

- $\quad$ El tiempo intermedio, el que corresponde al desierto-camino, es una experiencia primordial y símbolo del hombre; por medio de esta, se libera del entorno y domina el espacio, pero al mismo tiempo esta capacidad radical de 'infinitud' se une a su incapacidad de finitud. Es por eso que el Señor se presenta con dos fórmulas arquetípicas: por un lado, un hacedor de prodigios y, por el otro, Yahvé guía, que va adelante y acompaña en el viaje, por medio de la columna o del Arca.

- El punto privilegiado del entrar es la tierra, que en muchas oportunidades es un lugar sacro, un lugar prolongado y abierto. La tierra es presentada como una realidad estable, permanente bajo los pies, anualmente fecunda y más duradera que las generaciones. La tierra es la expresión de la bendición prometida al pueblo.

- Por último, la condición para ponerse en marcha es la aceptación con fe y esperanza del mensaje divino.

Creemos que teniendo en cuenta esta propuesta, podemos reconocer el paradigma del éxodo no solo como unificador del Salmo 121, sino también como un canto actualizado del evento salvífico-bendición de ahora y para siempre, a través de las siguientes etapas:

\section{i. Anuncio de una partida (Ax)}

El salir es un movimiento de lo cerrado a lo abierto. Por ejemplo, Abraham tuvo que salir de su cultura y tierra, cerrada en un contexto determinado, hacia un espacio abierto del encuentro con el Señor. También en sus entrañas, su descendencia estaba encerrada, no podía salir fuera para multiplicarse como las estrellas del cielo. En esa partida del país de Ur y en la acogida de los tres hombres en la 
encina de Mambré, es donde Abraham se confía en la palabra del Señor y es esto lo que representa su mérito.

En este paradigma es frecuente que el verbo salir sea sustituido por subir. La región de Palestina es montañosa y, contemplada desde Egipto (una zona baja), salir es subir. Lo mismo ocurre en las peregrinaciones hacia el monte Sión: como decíamos más arriba, siempre se sube a Jerusalén.

La expresión "alzar (mirar) hacia los montes" del v. 1, en correlación con las imágenes de movimiento tanto del v. 3, "no resbalar a tu pie", como la del v. 8 , "tu salir y tu entrar", nos ayuda a reconocer en la primera estrofa un anuncio de un viaje. Ante la inminencia de la partida, el peregrino, protagonista de esta etapa, debe poner toda su confianza en el Señor y expresar en su interior, o con la ayuda de otra voz, de dónde viene su auxilio.

Los montes son presentados al comienzo del camino con su imagen polivalente, como lugar de morada divina, refrendada luego con la referencia a la sombra del v. 5, o como lugar de peligro, ante el cual el peregrino necesita protección y cuidado. En Éxodo $(15,17)$, el poeta celebra el final del camino, la entrada “[...] en el Monte de tu heredad, en el lugar donde has preparado, Yahvé, tu morada, en el santuario que tus manos, Señor, han afirmado". La seguridad de la llegada, lugar de acogida y a la vez de protección por la presencia divina, atrae, pone en movimiento, da seguridad a la partida del peregrino.

\section{ii. El camino (Cy)}

El tiempo del camino es el lugar de peligros, en el que la seguridad de los montes (imagen positiva) es reemplazada por la perspectiva negativa, que se sintetiza en la realidad del desierto. Entre las necesidades básicas del desierto está el cubrirse y esta es una de las acciones protectoras del Señor en la tercera estrofa del Salmo 121 (la función de la sombra del v. 5, que se concretiza en la protección de los efectos del sol, durante el día, y de la luna, durante la noche, en el v. 6, es la misma de "la nube de Yahvé sobre ellos" de Nm 10, 34).

Los peligros del camino se descubren a través de las intervenciones divinas, que en la segunda y tercera estrofas manifiestan una suerte de aumento, desde afirmaciones negativas ("que no permite, que no duerme") hacia acciones más durativas ("tu guardián, tu sombra sobre tu mano derecha").

El verbo cuidar-guardar en los vv. 3, 4, 5, 7 y 8 hace eco, de una manera insistente, de la acción de Yahvé a lo largo de todo el camino del Éxodo, como está expresado en Josué $(24,17)$ : "[...] nos guardó por todo el camino que recorrimos". 
L. A. Schökel sostiene que en este tiempo intermedio, el del camino, "uno a uno va despachando el desierto sus agentes mortales, uno a uno va debelando a Yahvé, con sus maravillosas intervenciones" (Schökel, 1980, p. 106). Nada resiste a la acción creadora de Dios $^{19}$.

El protagonista en esta etapa del paradigma es Yahvé. El Señor es quién transforma el desierto, por naturaleza infecundo e inhumano, y lo carga de historia, de salvación y de significado por efecto de la presencia del pueblo de Dios. Al pueblo le queda vivir esta fase del proceso, entre la salida de Egipto hasta la entrada en Canaán, como un período de aprendizaje importante, en el que debe comprender que el Señor es el centro de su vida (Magnate, 1991, p. 54).

\section{iii. Entrada como una bendición (Bz)}

El Señor continúa siendo el protagonista que bendice a través de su presencia protectora a un tú con expresiones opuestas y polares que engloban la totalidad de la vida de la persona: "no permite resbalar a tu pie", "no duerme tu guardián", "el Señor tu guardián”, "el Señor tu sombra”, "sobre tu mano derecha", "el sol no te hará daño", etc.

El Éxodo de Egipto se enraíza en la expresión polar salir-entrar, que en el Salmo 121 la encontramos en el v. 8 (Schökel, 1980, pp. 24-25) y se transforma en un modelo común para todos los relatos de éxodos ${ }^{20}$.

M. Liverani llama a este par de verbos la fórmula o código motor del éxodo (Liverani, 2004, pp. 330-331); esta la encontramos presente en varios textos del libro del Éxodo desde donde podemos verificar la correspondencia con el Sal 121, 8. Salir lo hallamos en Ex 6,7; 13,3.4.8, con dos claves que unifican los textos: la primera es que el lugar de donde se sale es Egipto, y la segunda es una referencia clara a la liberación obrada en ese mismo acto de partida. Entrar en Ex 6,8; 15,17,

19 L. A. Schökel desarrolla la tensión-resistencia expresada en el camino por las realidades cósmicas (Schökel, 1980, pp. 105-106). Para la literatura judía, los demonios matutinos y vespertinos son amenaza y resistencia para el que quiere ser fiel a Yahvé. Así, según Lenzi, "[l]a ripartizione dei demoni a seconde del tempo è tipica nelle opere targumiche, vedi ad es. il Targum Pseudo-Jonathan a Nm 6,24: Il Signore ti custodisca dai Notturni, dai Terrificanti, dai Meridiani, dai Mattutini e dai Tenebrosi" (2000, p. 88).

20 L. A. Schökel habla de tres éxodos: el primero, el regreso de Egipto a la tierra de Canaán; el segundo, la salida de Babilonia y la vuelta a la patria, y el tercero, la salida de la diáspora en el reino escatológico (Schökel, 1980, p. 15). 
siempre en referencia a Canaán, vista esta como heredad, la Tierra Prometida a los padres.

Por lo tanto, los verbos salir-entrar no solo hacen mención a una migración geográfica, sino principalmente a una experiencia de liberación, en la cual el Señor es el protagonista que hizo salir de Egipto - esto es, de la esclavitud - al pueblo y lo hizo entrar a la tierra de la promesa; un movimiento, que a partir de la expresión polar salir y entrar del Salmo 121, 8, englobante de la totalidad de la vida y del quehacer humano, pasa a ser signo y canto de todos los procesos liberadores del ser humano, de todas las salidas de esclavitud, enfermedad, desolación, tristeza y muerte.

El libro del Éxodo (40,34-38) concluye indicando un futuro que está en las manos de Dios y bajo su protección y cuidado. Para llegar al final de camino, el pueblo se debe confiar en esa presencia, para que una vez terminado su éxodo, pueda gozar de la bendición divina (Spreafico, 1995, p. 214).

La perspectiva final de la salida, desde esta lectura, es una bendición, que en el Salmo 121 es una promesa de cuidado y protección de la totalidad de la vida "desde ahora y para siempre". Esta bendición está en sintonía con el último versículo del cántico de Éxodo $(15,18)$ : “[...] el Señor reinará eternamente y por siempre".

Cuando el pueblo esté en la tierra, lugar de bendición y de abundancia, deberá recordar que Yahvé fue su Guardián a lo largo del camino. El recuerdo en el presente del Señor que hizo todo lo creado, Pastor de Israel y Protagonista de su liberación, renovará la confianza del salmista ante todas sus salidas y entradas, confiando en la promesa divina que lo "cuidará de todo mal, [que] cuidará tu vida". 


\section{Referencias}

(1975). La Biblia de Jerusalén. Bilbao: Editorial.

(1988). La Bible. Traduction cecuménique de la Bible. Pierrefitte : Editorial.

Beaucamp, E. (1979). Le Psautier, Ps 73-150. Paris: Librairie Lecoffre.

Beauchamp, P., y Natalini, G. (1983). Salmi notte e giorno. Cittadella.

Bonnard, P. (1956). L'Esprit saint et l'Eglise selon le Nouveau Testament. Presses Universitaires de France.

Brown, F., Driver, S. R., y Briggs, C. A. (Ed.) (2006). A Hebrew and English Lexicon of the Old Testament. Massachusetts: Editorial.

Ceresko, A. (1989). Psalm 121: A Prayer of a Warrior, Biblica, 70(4), 496-510.

Dahood, M. (1970). Psalms III (101-150) in the Anchor Bible. New York: Double Day.

Elliger, K. y Rudolph, W. (Eed.) (1997)., Biblia Hebraica Stuttgartensia. Stuttgart: Editorial.

Fokkelman, J. P. (2003). Major Poems of the Hebrew Bible, at the Interface of Prosody and Structural Analysis. Volume III: The Remaining 65 Psalms. Assen.

Gesenius, F. W., y Kautzsch, E. (1910). Gesenius' Hebrew Grammar. (A. E. Cowley, trad.) Oxford: Editorial.

Gunkel, H., Introducción a los salmos. (trad. al castellano por Díaz Rodelas J. M.), Valencia 1983.

Haglund, E. (1984). Historical motifs in the Psalms. Lund, Sweden: CWK Gleerup.

Jacquet, L. (1975). Les Psaumes et le coeur de l'homme: Étude textuelle, littéraire et doctrinale. Gembloux: Duculots.

Jenni, E., y - Westermann, C. (1985). Diccionario teológico manual del Antiguo Testamento. Madrid 1985, I-II: Editorial.

Joüon, P., y Muraoka, T. (2007). Gramática del hebreo bíblico. (M. Pérez Fernández, Ed.). Navarra: Editorial.

Kimchi, D. (2001). Commento ai Salmi, III: Sal 101-150. (Tradizione d'Israele). Roma: Editorial.

Kraus, H. J. (1985). Teología de los salmos. (Martínez de Lapera V. A., trad.). Salamanca.

Kraus, H. J. (1995). Los Salmos I - Los Salmos II. Madrid 1995: Editorial.

Lenzi, G. (Ed.) (2000). I Salmi del pellegrinaggio: Shirei ha-Ma'alot (canti dei gradini). Roma.

León-Dufour, X. (1996). Vocabulario de teología bíblica. (Ed. revisada y ampliada)., Barcelona: 1996Editorial. 
Levenson, J. D. (1987). Sinai \& Zion: an entry into the Jewish Bible. (p. 82). New York: Harper \& Row.

Liebreich, L. J. (1955). The Songs of Ascents and the Priestly Blessing. Journal of Biblical Literature. 33-36.

Liverani, M. (2004). Más allá de la Biblia: historia antigua de Israel. Barcelona: Editorial Crítica.

Magnate, A. (1991). La teologia dell'Esodo nei Salmi. Roma.

Mello, A. (1998). L'arpa a dieci corde. Introduzione al salterio. Magnano (Biella): Qiqajon.

Mello, A. (2006). L'ordine dei salmi. LA, 56, 47-70.

Morla Asensio, V. (1994). Libros sapienciales y otros escritos. Navarra.

Navarro Puerto, M. (1996). El libro del Éxodo. ResB, 9, 23-32.

Niccacci, A. (1997). Analysing Biblical Hebrew Poetry. Journal for the Study of the Old Testament. (74), 77-93.

Niccacci, A. (2001). Poetic Syntax and Interpretation of Malachi. Liber Annuus. 51(1), 55-107.

Niccacci, A. (2002). Sintaxis del hebreo bíblico. Navarra: Editorial.

Niccacci, A. (2006). "The Biblical Hebrew Verbal System in Poetry. En", S. Fassberg, S. E. - Hurvitz, Fassberg, y A. Hurvitz, Biblical Hebrew in Its Northwest Semitic Setting: Typological and Historical Perspectives. Eisenbrauns. A. (eds.), Biblical Hebrew in Its Northwest Semitic Setting. Typological and Historical Perspectives, Jerusalem 2006.

Niccacci, A. (2009). Sintassi avanzata di ebraico biblico. (dispensa accademica). Gerusalemme 2009.

Niccacci, A., Pazzini, M., y Tadiello, R. (2004). Il libro di Giona. Jerusalem: Editorial.

Petruzzi, H., - Ruíz, E., y - Bannon, M. (1998). Gramática. Curso de Lengua Tomo la Palabra 7 EGB. Buenos Aires: Editorial 1998.

Rahlfs, A. (Ed.) (1984). Septuaginta. Stuttgart: Editorial.

Ravasi, G. (1983). Il libro dei Salmi I (1-49) - Il libro dei Salmi III (101-150). Bologna 1983: Editorial.

Ravasi, G. (2002). Los salmos. Madrid.

Real Academia Española. (2001). Diccionario de la Lengua Española. Madrid: Autor.

Scherman S., y Meir, Z. (2004). Tehilim. A New Translation with a Commentary Anthologized from Talmudic, Midrashic and Rabbinic Sources. New York: Editorial.

Schökel, L. (1980). Salvación y liberación: Apuntes de soteriología del Antiguo Testamento. Cuadernos Bíblicos. 5, 1-130.

Schökel, L. (1981). Treinta salmos: poesía y oración. Madrid. 
Schökel, L. (1987). Manual de poética hebrea. Madrid: Editorial.Scherman S. - Meir Z., Tehilim. A New Translation with a Commentary Anthologized from Talmudic, Midrashic and Rabbinic Sources. New York 2004.

Schökel, L. (1989). Interpretación de los Salmos hasta Casiodoro: Síntesis histórica. Estudios bíblicos. 47, 5-26.

Schökel, L. (1999). Diccionario bíblico hebreo-español. (V. Morla y V. Collado, Ed.). Madrid: Editorial.

Schökel, L. A. (1981). Treinta salmos: poesía y oración. (Vol. 2). Madrid: Ediciones Cristiandad.

Schökel, L. A., y Carniti, C. (1994). Salmos: II. (Salmos 73-150). Navarra: Editorial Verbo divino.

Spreafico, A. (1995). Guía espiritual del Antiguo Testamento. El libro del Éxodo. (trad. M. Villanueva Salas). Barcelona-Madrid.

Stec, M. D. (2004). The Targum of Psalms. Collegeville.

Waltke, B. K., y O'Connor M. (1990). Introduction to Biblical Hebrew Syntax. Winona Lake: Editorial.

Watson, W. G. (1986). Classical Hebrew poetry: a guide to its techniques. Sheffield: Publishing.

Weiser, A., (1984). I Salmi 61-150. Traduzione e commento, Brescia 1984: Editorial.

Zerwick, M., y Grosvenor, M. (2008). Análisis gramatical del griego del Nuevo Testamento. (J. Pérez Escobar, trad.). Navarra: Editorial. 